\title{
Fox-Fordyce Disease
}

"Gonzalo Blasco-Morente, ${ }^{1}$ María J. Naranjo-Díaz, ${ }^{1}$ Israel Pérez-López, ${ }^{1}$ Antonio Martínez-López, ${ }^{1}$

Ricardo Ruiz-Villaverde, ${ }^{1}$ José Aneiros-Fernández ${ }^{2}$

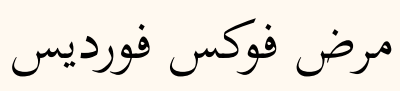

جونزالو بلاسكو-مورينتى، ماريا خوسيه نارانخو-دياز، إسرائيل بيريز-لوبيز، أنطونيو مارتينيز-لوبيز، ريكاردو رويز-فيلافيرد،

$$
\text { خوسي أنيروس-فرنانديز }
$$
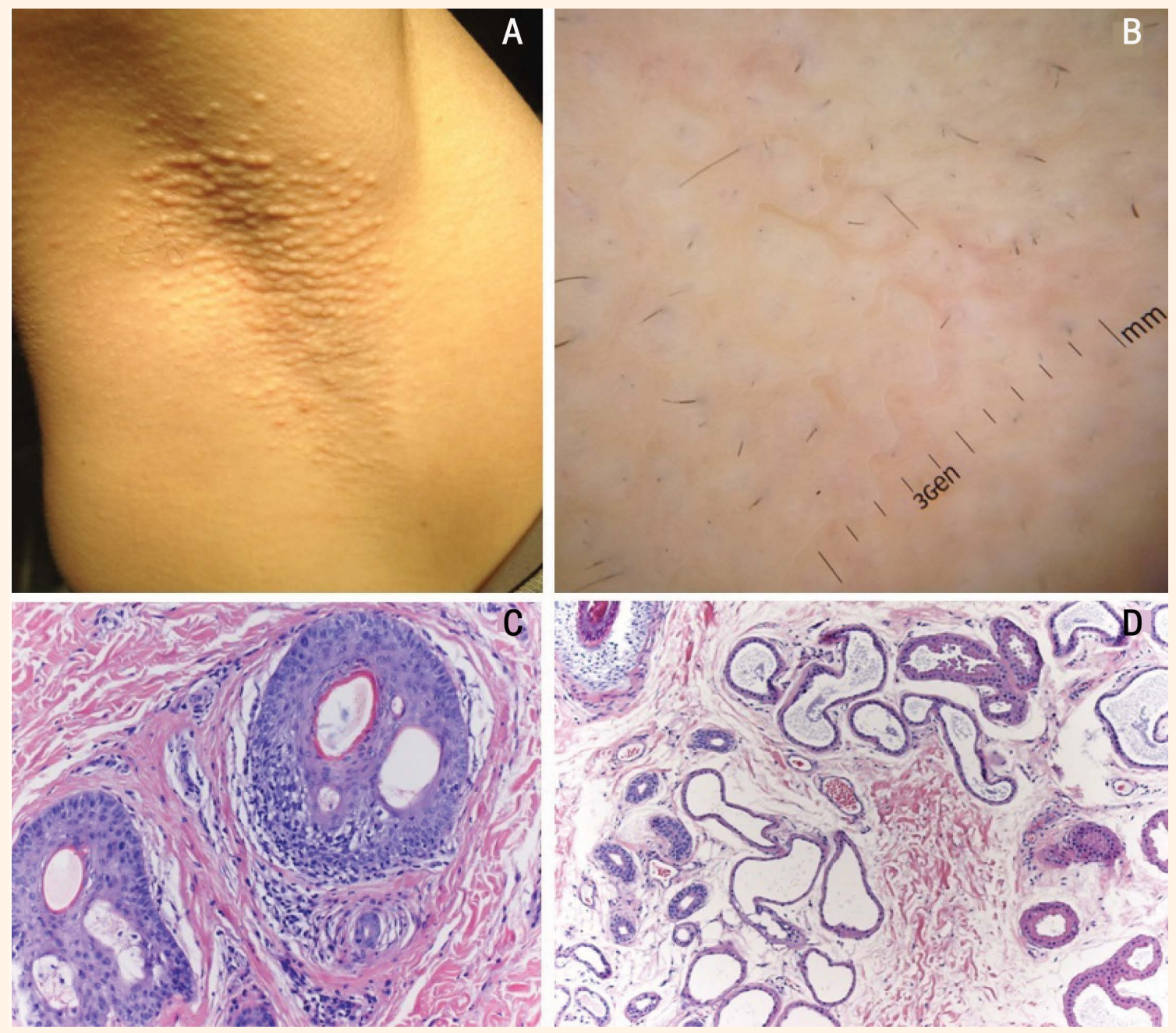

Figure 1A-D: A 42-year-old woman with Fox-Fordyce disease with (A) skin coloured papules of 1-2 mm and moderate alopecia in the right axilla and (B) folliculocentric papules with a few traumatised terminal hairs and blackheads. Haematoxylin and eosin stains showed $(\mathbf{C})$ inflammatory infiltrate of lymphocytes affecting the follicle at $x 10$ magnification and (D) eccrine and apocrine sweat glands showing dilatation at $x 4$ magnification.

A 42-YEAR-OLD WOMAN PRESENTED TO THE Department of Dermatology \& Venereology, Virgen de las Nieves Hospital, Granada, Spain, in May 2015 with a severe pruritic rash and hair loss in both axillary regions. Physical examination showed skin coloured papules and alopecia [Figure 1A], which showed no fluorescence under a Wood's lamp. Dermoscopy revealed hair follicle-centred papules, 
traumatised terminal hairs and blackheads [Figure 1B]. The histology of the skin biopsy indicated an inflammatory infiltrate of lymphocytes affecting the follicle [Figure $1 \mathrm{C}$ ] and the obstruction of the eccrine and apocrine sweat glands [Figure 1D]. The patient was diagnosed with Fox-Fordyce (FF) disease. Following treatment with tretinoin $(0.05 \%)$, she demonstrated moderate symptomatic improvement.

\section{Comment}

FF disease is a rare and chronic condition usually seen in adolescent women which affects the apocrine gland-bearing areas. The underlying aetiology of FF remains unclear, although a history of trauma caused by laser hair removal or hormonal factors may be triggers. ${ }^{1-4}$ The pathophysiology consists of the obstruction of the apocrine gland duct due to the insertion of a keratin plug in the hair follicle wall. This causes secretion retention with consequent rupture of the glandular structure and secondary inflammation of the dermis. ${ }^{2,3}$ The extravasation of the glandular content can be the cause of the pruritus. ${ }^{3}$ Clinically, the lesions are uniform, firm, folliculocentric papules, which can range in colour from normal skin colour to slightly brownish. ${ }^{3-5}$ The axillae are the most common areas involved, as in the present case, although FF also can involve the anogenital and periareolar areas, lips, umbilicus, sternum, perineum and upper medial aspects of the thighs. ${ }^{3,4}$

The diagnosis of FF disease is based on characteristic clinical features, as well as non-specific histopathological features. ${ }^{1-5}$ The histopathological features include dilatation of the follicular infundibula with hyperkeratosis, acanthosis and spongiosis of the infundibular epithelium and perifollicular infiltration of lymphocytes and foamy histiocytes, leading to hair loss. ${ }^{3-5}$ Differential diagnoses which can be considered include Graham-Little-Piccardi-Lasseur syndrome and trichostasis spinulosa; however, patients with FF disease would not have cicatricial alopecia or lesions elsewhere on the body or the mucosa. ${ }^{5}$

Various treatments for FF disease have been suggested with limited improvement, including the administration of oral contraceptives; topical, intralesional or systemic corticosteroids; topical clindamycin; pimecrolimus; phototherapy; surgical treatments like electrocoagulation and curettage with liposuction; and topical and oral retinoids, as prescribed in the current case. ${ }^{1-5}$

\section{References}

1. Kassuga LE, Medrado MM, Chevrand NS, Salles Sde A, Vilar EG. Fox-Fordyce disease: Response to adapalene 0.1\%. An Bras Dermatol 2012; 87:329-31. doi: 10.1590/S0365-059620 12000200029.

2. Kao PH, Hsu CK, Lee JY. Clinicopathological study of FoxFordyce disease. J Dermatol 2009; 36:485-90. doi: 10.1111/ j.1346-8138.2009.00689.x.

3. Yost J, Robinson M, Meehan SA. Fox-Fordyce disease. Dermatol Online J 2012; 18:28.

4. Milcic D, Nikolic M. Clinical effects of topical pimecrolimus in a patient with Fox-Fordyce disease. Australas J Dermatol 2012; 53:e34-5. doi: 10.1111/j.1440-0960.2010.00711.x.

5. George A, Bhatia A, Thomas E. Fox-Fordyce disease: A report of 2 cases responding to topical clindamycin. Indian J Dermatol Venereol Leprol 2015; 81:87-8. doi: 10.4103/0378-6323.148597. 